Ann Emerg Med. 2015 March ; 65(3): 345. doi:10.1016/j.annemergmed.2014.11.003.

\title{
In-Flight Emergency
}

\author{
Jonathan C. Horton, MD, C. PhD \\ University of California, San Francisco, San Francisco, California, USA
}

\section{Keywords \\ zolpidem; in-flight emergency; Wernicke aphasia; insomnia; sedative}

Last month I was called to assist a passenger on a flight from Boston to San Francisco, who was reported to be behaving strangely. I encountered an elderly man, washing his cell phone with a napkin soaked in orange juice. He was alert and spoke fluently, but his speech was incoherent and he followed no commands. According to seatmates, his condition had deteriorated steadily since takeoff. Heart rate, blood pressure, and respirations were normal. A brief neurological exam, performed while I knelt in the aisle, was intact except for altered mental status. 20 grams of sugar dissolved in juice produced no improvement. Because he was traveling alone and could not communicate, I had no information about him.

I was unsure of the diagnosis but considered the possibility of acute stroke, causing a Wernicke aphasia. The copilot and I discussed whether to divert the flight to Minneapolis. The patient's life did not appear in danger, so we decided to continue on to San Francisco. The plane was met by paramedics who transported the patient to a local hospital emergency room.

The next day I received a phone call from the patient, who was completely back to normal after a night in the hospital. He explained, apologetically, that he had taken zolpidem $10 \mathrm{mg}$ to help him sleep on the plane.

Possible stroke and altered mental status account for $4.4 \%$ of in-flight emergencies. ${ }^{1}$ It is unknown what percentage of passengers uses sleeping pills on airplane flights, but the general use of sedative hypnotics has escalated sharply. ${ }^{2}$ Zolpidem can produce paradoxical alertness, confusion, and automatisms. ${ }^{3}$ It accounts for $21 \%$ of emergency rooms visits for drug reactions to psychiatric medications in adults 65 years or older - more than any other medication. ${ }^{4}$ Physicians should caution patients, especially those traveling alone, about the potential risks of taking hypnotics when traveling by airplane.

\section{References}

1. Peterson DC, Martin-Gill C, Guyette FX, et al. Outcomes of medical emergencies on commercial airline flights. N Engl J Med. 2013; 368:2075-2083. [PubMed: 23718164]

Corresponding author: Jonathan C. Horton MD, PhD, University of California, San Francisco, hortonj@ vision.ucsf.edu, 10 Koret Way, San Francisco, CA, 94143-0730, Phone: 415-476-7176, Fax: 415-476-8309.

There are no conflicts of interest pertaining to this report 
2. Bertisch SM, Herzig SJ, Winkelman JW, Buettner C. National use of prescription medications for insomnia: NHANES 1999-2010. Sleep. 2014; 37:343-349. [PubMed: 24497662]

3. Poceta JS. Zolpidem ingestion, automatisms, and sleep driving: a clinical and legal case series. $\mathbf{J}$ Clinical Sleep Med. 2011; 7:632-638. [PubMed: 22171202]

4. Hampton LM, Daubresse M, Chang HY, Alexander GC, Budnitz DS. Emergency department visits by adults for psychiatric medication adverse events. JAMA Psychiatry. 2014; 71:1006-1014.

[PubMed: 25006837] 